\title{
TRADING STRATEGIES WITH COPULAS
}

\author{
Yolanda Stander* \\ University of Johannesburg \\ yolanda.Stander@gmail.com
}

\section{Daniël Marais"}

Prevision

danielmarais@mweb.co.za

\author{
Ilse Botha+ \\ University of Johannesburg \\ ilseb@uj.ac.za
}

February 2012

\begin{abstract}
A new approach is proposed to identify trading opportunities in the equity market by using the information contained in the bivariate dependence structure of two equities. The relationships between the equity pairs are modelled with bivariate copulas and the fitted copula structures are utilised to identify the trading opportunities. Two trading strategies are considered that take advantage of the relative mispricing between a pair of correlated stocks and involve taking a position on the stocks when they diverge from their historical relationship. The position is then reversed when the two stocks revert to their historical relationship. Only stock-pairs with relatively high correlations are considered. The dependence structures of the chosen stock-pairs very often exhibited both upper- and lower-tail dependence, which implies that copulas with the correct characteristics should be more effective than the more traditional approaches typically applied. To identify trading opportunities, the conditional copula functions are used to derive confidence intervals for the two stocks. It is shown that the number of trading opportunities is highly dependent on the confidence level and it is argued that the chosen confidence level should take the strength of the dependence between the two stocks into account. The backtest results of the pairs-trading strategy are disappointing in that even though the strategy leads to profits in most cases, the profits are largely consumed by the trading costs. The second trading strategy entails using single stock futures and it is shown to have more potential as a statistical arbitrage approach to construct a portfolio.
\end{abstract}

\section{Keywords}

copulas, pairs-trading, single stock futures, mean reversion, stock price drift, trading costs, backtest, hedge funds, statistical arbitrage

\footnotetext{
*Ms Yolanda Stander is a PhD-student at the Faculty of Economics \& Financial Sciences, University of Johannesburg, South Africa.

\#Prof Daniel Marais is a researcher in the Department of Economics and Econometrics at the University of Johannesburg, South Africa

+Dr Ilse Botha is a senior lecturer at the Department of Finance \& Investment Management, University of Johannesburg, South Africa
} 


\section{INTRODUCTION}

Harry Markowitz proposed a basic portfolio model based on the relationship between the expected return of the portfolio and the riskiness of the portfolio, which are typically measured as the variance of the returns (Markowitz, 1952). The Markowitz theory is built around the assumption that investors base their decisions solely on the returns expected at a given level of risk. In general, investors prefer higher returns to lower returns, and, for a given level of return, investors prefer lower risk to higher risk. A portfolio is considered to be efficient if no other portfolio of assets offers a higher expected return with the same or lower level of risk. The efficient frontier is a graphical way to decide on the optimal portfolio. The idea is to plot the expected portfolio returns against the riskiness of the portfolio for different combinations of assets. The efficient frontier is an envelope graph that is used to depict the portfolios with the best combinations of assets, in other words, those portfolios with the highest return and the lowest risk given that level of return. Please refer to Reilly and Brown (2006) for a more detailed discussion.

The Markowitz mean-variance approach is based on the portfolio's linear expected return and volatility. Practitioners typically use logarithmic returns, which Meucci (2001) argues are mathematically inconsistent and lead to suboptimal asset allocation. The Markowitz model is very sensitive to the calculated returns and often leads to unstable asset weights. An optimisation routine often leads to extreme portfolio weights when constraints are used. Some practitioners find the Markowitz model unintuitive because the model does not incorporate the investor's point of view or provide any indication of the confidence level of the results. The Black-Litterman model is an example of a model that addresses this problem. The BlackLitterman model uses a Bayesian approach to combine the subjective views of the investor with the actual market distribution of returns (prior distribution) to form a new posterior distribution (Black \& Litterman, 1990; Meucci, 2008). The model assumption is that both the prior and the subjective views can be modelled with a Gaussian distribution. The investor expresses views on the distribution parameters, because it is easy to interpret the parameters of the Gaussian distribution. The problem with this approach is that market returns are generally not Gaussian and the parameters of the distributions that allow for fat-tails and skewness are not as easy to interpret. This led to the development of the copula-opinion-pooling approach, which provides a methodology to get to a posterior market distribution that smoothly blends an arbitrary market prior distribution with an arbitrary investor view of the market distribution. Instead of expressing views on the parameters, the investor expresses views directly on market realisations. Asset allocation is then performed using the expected return/expected shortfall approach, which accounts for asymmetric distributions with heavy tails (Meucci, 2005; 2006).

Stock-pair trading has traditionally depended on the implicit assumption of Gaussian distributions. In this article a different approach to this particular field of portfolio construction is proposed. Instead of focusing on the risk-return relationship, the focus is to model the relationship between stock pairs using bivariate copulas and then to use the fitted copula structures to identify trading opportunities in the market. The bivariate copula more accurately captures the dependence structure between the equity pairs and allows for the characteristics of the individual stock price distributions such as asymmetry and heavy-tailedness.

The importance of allowing for asymmetric distributions with heavy tails in South African equities stems from the various studies that consider the differences in the behaviour of key market variables in emerging and developed markets. Emerging markets are typically subject to 
more extreme shocks than their developed counterparts and the higher degree of volatility leads to key variables that exhibit more heavy-tailed distributions (Ibragimov, Davidova \& Khamidov, 2010; Oskooe \& Shamsavari, 2011). Ghysels, Plazzi and Valkanov (2011) show that the low correlation between the asymmetric key variables across developed and emerging markets can be explained by the markets reacting differently to macroeconomic fundamental factors. Researchers expect an increasing growth gap between emerging and developed markets, because the equities in developed markets will be constrained by slow growth in the underlying economies (Thambiah \& Foscari, 2012).

Studies also show that the impacts of stress events in emerging markets are not necessarily the same. Oskooe and Shamsavari (2011) show that the general view that stock market volatility tends to be greater in a falling market than in a rising market, does not apply to the Iranian market. Their results indicate that positive and negative shocks of the same magnitude have the same impact on the volatility. In contrast to this result, Khedhiri and Muhammad (2008) show that for the UAE stock market, a stock price decrease has a greater impact on the volatility than a stock price increase of the same magnitude. Su (2010) confirms this result for the Chinese stock market. Allen, Golab, and Powell (2010) study the relationships in the 12 emerging markets in Central and Eastern Europe and show that, of these emerging markets, the ones recognised as advanced emerging markets appear to be more sensitive to all shocks from other developed markets around the world.

The pairs-trading strategy is one of common statistical arbitrage approaches used by hedge funds (Connor \& Lasarte, 2004). Unlike the Markowitz-type approach, the stock-pair constructed portfolio is a short-term portfolio that needs active management.

A different hedge fund strategy is introduced by Patton $(2002,2004)$ where copulas are used to create index-tracking portfolios by maximising the excess return calculated with utility functions. The idea has been extensively explored by other researchers and is not considered in this paper. Consider for instance the work by Hennessy and Lapan (2002) and Chu (2011).

The outline of this article is as follows. Section 2 provides a brief introduction into bivariate copulas. In Sections 3 and 4 the pairs-trading and single-stock futures (SSF) trading strategies respectively are discussed and in Section 5 the approach followed to calculate the number of shares to buy/sell is explained. Section 6 summarises the trading costs that have to be allowed for in the backtest analyses and in Section 7 practical applications of both trading strategies are illustrated. Conclusions are drawn in Section 8.

The methodologies are illustrated by focusing on the equity market. However, the techniques can easily be extended to other asset classes such as foreign exchange and commodities.

\section{BIVARIATE COPULAS}

Abe Sklar defined a copula by showing the relationship between the multivariate distribution function and the copula function which joins the marginal distribution functions (Sklar, 1959). Archimedean copulas form a different class of copulas in that they are not defined in terms of Sklar's theorem, but are derived using generator functions that have very specific properties.

Let $\varphi$ be a continuous and strictly decreasing generator function from $I$ to $[0, \infty)$ such that (1) $=0$. The Archimedean copula function $C$ is then given by 


$$
C(u, v)=\varphi^{[-1]}(\varphi(u)+\varphi(v))
$$

where $\varphi^{[-1]}$ is the pseudo-inverse of $\varphi$ and is defined as

$$
\varphi^{[-1]}(t)=\left\{\begin{array}{cl}
\varphi^{(-1)}(t) & , 0 \leq t \leq \varphi(0) \\
0 & , \varphi(0) \leq t \leq \infty
\end{array}\right.
$$

$C$ is a copula if and only if $\varphi$ is convex, that is $\varphi^{\prime \prime}>0$. If $\varphi(0)=\infty$ then $\varphi$ is called a strict generator function and it follows that $\varphi^{[-1]}(t)=\varphi^{(-1)}(t)$. The generator functions of some of the more popular Archimedean copulas are:

- Clayton: $\varphi(t)=\frac{1}{\alpha}\left(t^{-\alpha}-1\right), \alpha \in[-1, \infty) /\{0\}$

- Gumbel: $\varphi(t)=(-\ln t)^{\alpha}, \alpha \in[-1, \infty)$

- Frank: $\varphi(t)=-\ln \left(\frac{e^{-\alpha t}-1}{e^{-\alpha}-1}\right), \alpha \in[-\infty, \infty) /\{0\}$

- Joe: $\varphi(t)=-\ln \left(1-(1-t)^{\alpha}\right), \alpha \in[-1, \infty)$

- N13: $\varphi(t)=(1-\ln t)^{\alpha}-1, \alpha \in[0, \infty)$

- N14: $\varphi(t)=\left(t^{-1 / \alpha}-1\right)^{\alpha}, \alpha \in[1, \infty)$

Joe (1997) and Nelsen (2006) provide a comprehensive introduction to bivariate Archimedean copulas and their properties. The parameter $\alpha$ denotes the strength of the relationship between the two variables, where a higher $\alpha$ implies a greater dependence.

An interesting property of the Archimedean copulas is that the distribution function $K_{C}(t)$ of the random variable $C(U, V)$ can be derived from the generator function:

$$
K_{C}(t)=t-\frac{\varphi(t)}{\varphi^{\prime}\left(t_{+}\right)}
$$

The non-parametric counterpart of this distribution function is:

$$
\widehat{K}_{C}(v)=\frac{1}{n} \sum_{j=1}^{n} \operatorname{ind}\left(V_{j} \leq v\right)
$$

where $V_{j}=\hat{C}\left(u_{j}, v_{j}\right)$ for $j=1, K, n$ where $n$ denotes the number of observations in the sample. $\hat{C}$ denotes the empirical copula estimate. More information on the empirical copula can be found in Cherubini et al. (2004) and Patton (2012).

As part of the back-test analyses the parameters for each of the different Archimedean copulas are estimated using maximum likelihood estimation techniques. The Kolmogorov-Smirnov goodness-of-fit test can be used to indicate the best fit copulas. This test compares the distance between the parametric distribution function $K_{C}(t)$ and its nonparametric counterpart $\widehat{K}_{C}(v)$ under the null hypothesis. Please refer to Genest and Rémillard (2005) and Genest et al. (2007) for the details around the goodness-of-fit test and approaches to derive the $p$-value using bootstrap techniques. A good overview of available research can be found in Patton (2012). 


\section{PAIRS-TRADING STRATEGIES}

\subsection{Overview}

Pairs-trading strategies are based on either fundamental or technical analysis. Fundamental analysis requires extensive company research to identify stocks that are expected to move together. The analysis would consider accounting ratios like earnings-to-price and book-tomarket factors. Fundamental analysis is very expensive and time consuming.

Technical analysis is more common and requires statistical techniques to identify stock pairs and trading signals. There are various trading signals that are currently used by traders. The signals include (Agarwal et al., 2004; Chan, 2009; Do et al., 2006):

- The spread between the prices of the two stocks.

- The price ratio of two stocks.

- Determining the ranks of the stock prices and then considering the spread between the ranks.

- Regressing the two stocks and then computing the ranks of the residuals. A trading signal is recognised when the rank is more than two standard deviations away from the average rank.

- The distance method considers the sum of squared differences between the two normalised stock price series and trading is then triggered when the distance reaches a certain threshold, typically two standard deviations.

The pairs-trading strategy considered in this section is based on the technical analysis approach, but copula theory is used to identify the trading opportunities.

The importance of copulas in the various risk management disciplines has been explored extensively. Examples include McNeil, Frey and Embrechts (2005) for applications in the Credit, Market and Operational Risk fields; or Andersen, Bollerslev, Christoffersen and Diebold (2007) for applications in Market Risk. However, the focus of this paper is on how the information in the copula dependence structure can be used in trading strategies.

Copulas capture the level of mispricing as well as the strength of the mean reversion. The level of mispricing is captured by determining the probability associated with a market-observed value with respect to another market variable to which it was historically highly correlated. It is argued that the deeper into the tail of the distribution the market value lies, the stronger the mean reversion is expected to be. The concept will become more apparent in the next section where the ways in which trading opportunities are identified are discussed.

\subsection{Trading signals}

The copula function summarises all the characteristics of the dependence structure of two stocks. The information contained in the dependence structure of the two stocks is used to identify when the two stocks move away from each other or when one of the stocks show a move that is much higher or lower than expected given the historical relationship between the two stocks. The copula dependence structure is used to determine a confidence band. When a market observation falls outside the confidence band, it is an indication that a pairs-trading opportunity is available. 
The first step is to establish which copula adequately describes the dependence structure of the two stocks. The algorithm is as follows:

- Let $P_{X}$ and $P_{Y}$ denote the historical stock price series for stocks $X$ and $Y$ respectively. The $\log$-returns for the two stocks are derived using $R_{X}=\ln \left(\frac{P_{X, i}}{P_{X, i-1}}\right)$ and $R_{Y}=\ln \left(\frac{P_{Y, i}}{P_{Y, i-1}}\right)$ for $i=1, \ldots, n$ where $n$ denotes the number of historical stock prices in the dataset.

- Let $F_{X}$ and $G_{Y}$ denote the cumulative distribution functions for the return series $R_{X}$ and $R_{Y}$ respectively. The marginal distributions can be determined either by fitting parametric distribution functions using techniques like maximum likelihood estimation, or using a nonparametric approach like the empirical distribution function. The distribution functions will capture the characteristics of each of the return series, such as heavy-tailedness and asymmetry.

- The probability integral transform is used to convert the two return series to uniform variables $U=F_{X}\left(R_{X}\right)$ and $V=G_{Y}\left(R_{Y}\right)$. The assumption is that the variables are continuous.

- A copula function is fitted to the two uniform variables $U$ and $V$.
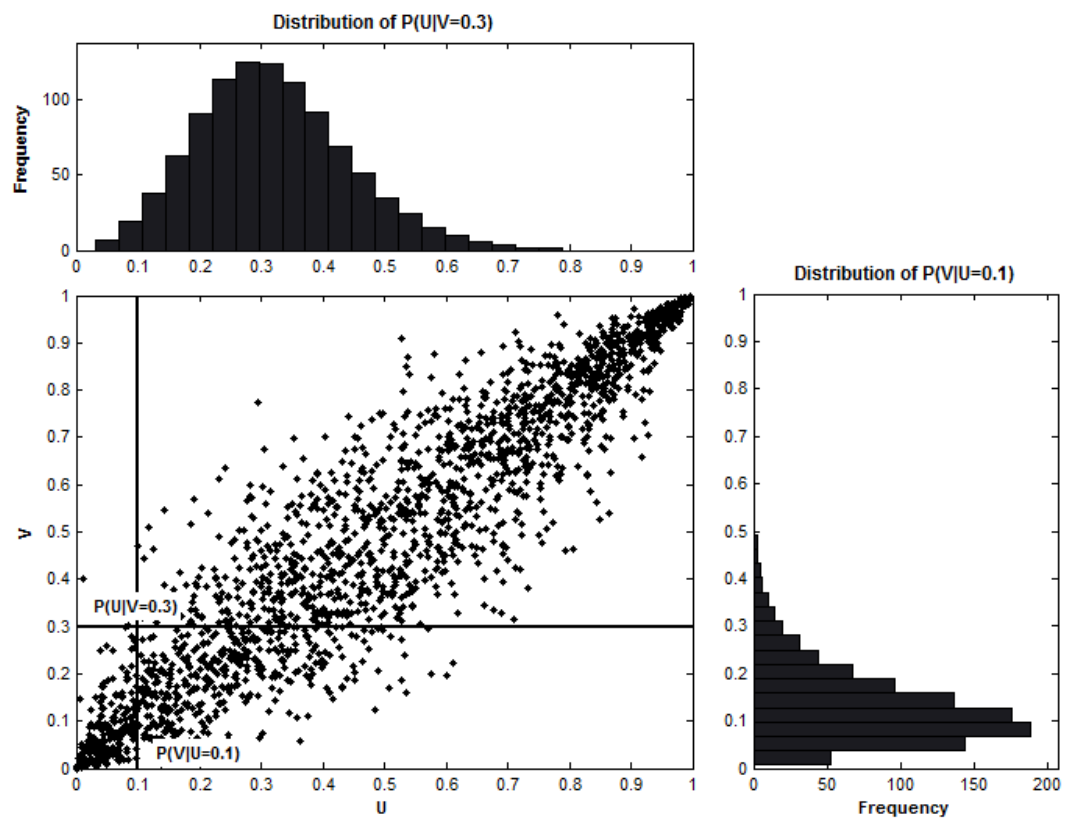

FIGURE 1: An illustration of the conditional distribution function of $V$ for a given value of $U$ and the conditional distribution function of $U$ for a given value of $V$ using the N14 copula dependence structure.

\section{Source: Representation of simulation study}

The fitted copula is used to derive the confidence bands for the conditional marginal distribution function of $V$ given $U$ denoted by $C(V \mid U=u)$, as well as for the conditional 
marginal distribution function of $U$ given $V$ denoted by $C(U \mid V=v)$. The idea is that when the confidence bands are breached, a trading opportunity is signalled.

To illustrate the idea, an example of the conditional distribution function $C(V \mid U=0.1)$ is shown in FIGURE 1 using the N14 copula structure to illustrate the methodology. FIGURE 1 shows that the conditional distribution function of $V$ is very skew, with most weight at the lower values of $V$. The $p^{\text {th }}$ percentile is calculated from the conditional distribution $C(V \mid U=0.1)$. By choosing a relatively high percentile, that percentile forms the upper bound for $V$ at the given value of $U$. Similarly it is possible to derive a lower bound from the $(1-p)^{\text {th }}$ percentile for $V$ at the given value of $U$. FIGURE 1 also illustrates the conditional distribution function of $C(U \mid V=0.3)$.

The upper and lower confidence bands of $C(U \mid V=v)$ are used to determine when stock $X$ moves in such a way that is out of line based on its historical relationship with stock $Y$, and the confidence bands of $C(V \mid U=u)$ are used to determine when stock $Y$ moves in such a way that is out of line given its historical relationship with stock $X$.
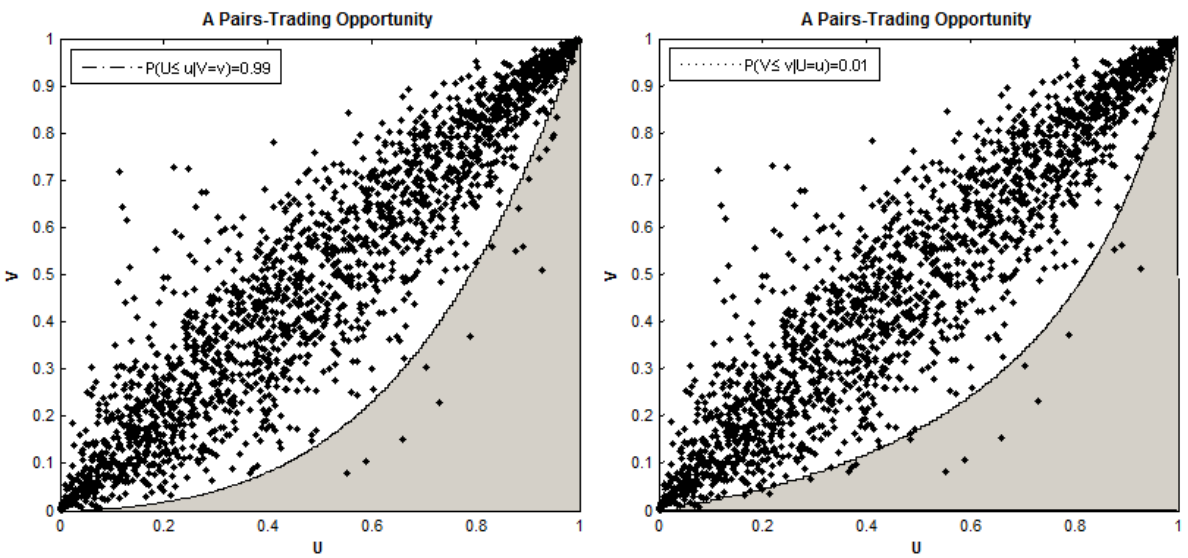

FIGURE 2: An illustration of the areas where the values of $\boldsymbol{U}$ and $\boldsymbol{V}$ respectively are considered extreme when using a $99 \%$ confidence level and the N14 copula dependence structure.

\section{Source: Representation of simulation study}

\subsubsection{Buy Stock $Y$ and sell Stock X}

The shaded areas in FIGURE 2 show where $U$ and $V$ respectively show extreme moves when using a $99 \%$ confidence level. The realised value of $U$ is relatively big in each case, which indicates that the price of stock $X$ has increased significantly. $O n$ the other hand, the realised value of $V$ is relatively small, which indicates that the price of stock $Y$ has decreased significantly.

The shaded area in FIGURE 3 shows where the two shaded areas in FIGURE 2 overlap and indicates where pairs-trades can be considered when using a $99 \%$ confidence level. Over this area the two stocks have moved away from each other more than expected, because the realised values fall outside the derived confidence bands. The trading strategy involves selling stock $X$ and buying stock $Y$. 
The assumption is that by using a confidence level of only $1 \%$ in the lower- and upper-tails of the conditional distributions of stocks $X$ and $Y$, the confidence levels are extreme enough to identify a trading opportunity.

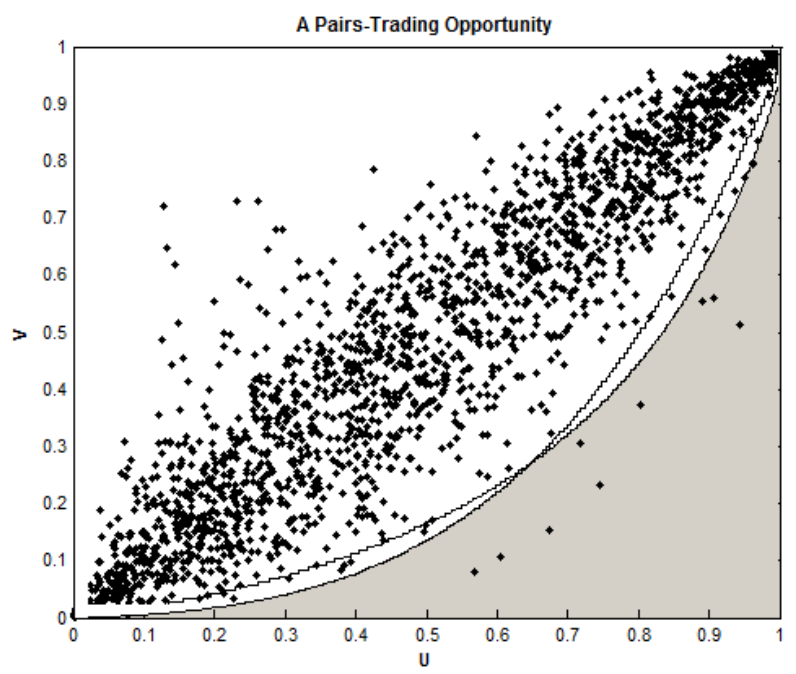

FIGURE 3: An illustration of the area where pairs-trades can be executed when using a $99 \%$ confidence level and the $\mathrm{N} 14$ copula dependence structure.

Source: Representation of simulation study

\subsubsection{Buy Stock $X$ and sell Stock $Y$}

The shaded area in FIGURE 4 shows the possible pairs-trading opportunities to buy stock $X$ and sell stock $Y$. The realised values of $U$ in that area are relatively small, which indicates that the price of stock $X$ has decreased significantly. Similarly, the realised values of $V$ are relatively big, which indicates that the price of stock $Y$ has increased significantly. The pairs-trade is triggered, because the two stocks moved away from each other significantly, and the observations fall outside the derived confidence bands. 


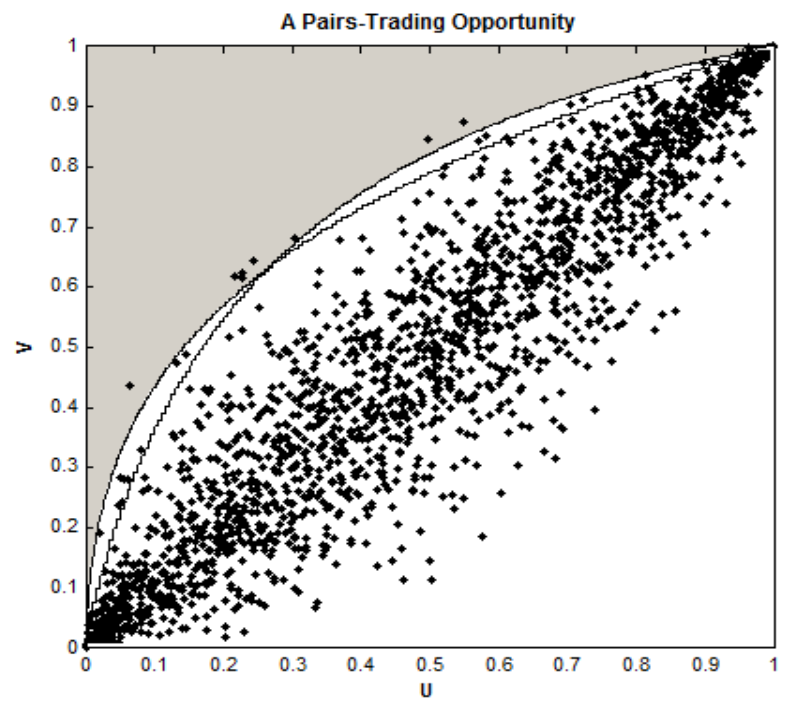

FIGURE 4: An illustration of the area where pairs-trades can be executed when using a $99 \%$ confidence level and the N14 copula dependence structure.

Source: Representation of simulation study

\subsection{Summary}

The pairs-trading strategy can be summarised as follows:

- Let $P_{X}$ and $P_{Y}$ denote the current market price of the two stocks. Use the previous observed market prices of the two stocks to derive the returns $R_{X}$ and $R_{Y}$.

- Convert the two returns $R_{X}$ and $R_{Y}$ to two uniform values $u$ and $v$ using the distribution functions $F_{X}$ and $G_{Y}$ of the two stocks.

- If the pair $(u, v)$ falls outside the confidence bands in the northwest quadrant, it is an indication to buy stock $X$ and sell stock $Y$. If the pair $(u, v)$ falls outside the confidence bands in the southeast quadrant, it is an indication to sell stock $X$ and buy stock $Y$. Otherwise, wait until new market prices become available for the two stocks.

- Decide how many of each stock to buy or sell and execute the trade.

- Exit the trade when the two stocks revert to their historical relationship. For instance, when buying stock $X$ and selling stock $Y$, a profit is locked in when unwinding the trade at the time when the price of stock $X$ increases and/or the price of stock $Y$ decreases.

A back-test analysis is typically performed to determine an adequate confidence level. By selecting a confidence level that is too low, a multitude of trading opportunities may be identified, but are often unlikely to lead to a large enough profit to cover trading costs. By selecting a confidence level that is too high, rather few trading opportunities are identified and profitable opportunities may be lost. 


\section{A STRATEGY WITH SINGLE STOCK FUTURES}

\subsection{Overview}

Single stock futures (SSFs) are exchange-traded derivatives with standard terms and conditions determined by the Johannesburg Stock Exchange (JSE). The SSF is a contract to buy or sell 100 units of a specific share that is listed on the JSE. The contracts have fixed expiry dates, typically specified as the third Thursday of every March, June, September and December. When the SSF contract expires, the buyer of the SSF takes delivery of the underlying shares. Please refer to JSE (2010) for more details on the SSF contracts.

The advantage of the SSF contract is that the holder of the contract is not expected to pay the full amount that the contract exposes him/her to; the holder is required to pay only an initial margin. When buying $n_{X}$ SSF contracts, the holder would be exposed to an amount

$$
V_{X}=n_{X} \times 100 \times S_{X}
$$

where $V_{X}$ denotes the total exposure and $S_{X}$ denotes the SSF contract price. Let $I M_{X}$ denote the initial margin, then the investor is only expected to pay an amount of $I M_{X} \times V_{X}$. The initial margin can typically be $10 \%$ to $30 \%$, and is a way to cover the institution against the highest possible trading loss in the underlying stock that is possible on any single day. The SSF thus allows for gearing, since, while less capital is required, the holder is still exposed to the full risk of the underlying shares.

The holder of the SSF is also required to pay a variation margin. The variation margin is defined as the profit or loss on each position as determined by the JSE at the end of each trading day. The variation margin is settled the next business day.

Another advantage of SSFs is that they allow the investor to also short-sell shares.

SSF prices are adjusted to compensate the holder for ordinary dividends on the underlying shares that may be receivable (or payable). The holder of the SSF does not earn dividends and is not liable to pay dividends. Special dividends and corporate actions are taken into account by the JSE by adjusting the quantity of the holder's SSF position.

There are two types of trading costs that have to be taken into account: the market maker's commission, which is around $0.4 \%$, and a brokerage fee that is set by the broker. Please refer to SBSA (2006) for an example of how the bid and offer prices are determined by brokers. The bid price is the price at which the institution is willing to buy a SSF and the offer price is the price at which the institution is willing to sell a SSF. The main driver of the price movement of the SSF is the price movement in the underlying share.

\subsection{SF Trading Strategy}

The pairs-trading strategy discussed in Section 3 can also be applied to single stock futures. In this section the trading strategy is adjusted slightly in that the stock selected for investment will only be that which shows the biggest relative move. In the SSF strategy the dependence structure between the underlying stocks is again analysed. However, when executing a trade, it is the SSF that is bought or sold. To summarise the SSF trading strategy:

- Let $P_{X}$ and $P_{Y}$ denote the current market price of the two stocks. Use the previous observed market prices of the two stocks to derive the returns $R_{X}$ and $R_{Y}$. 
- Convert the two returns $R_{X}$ and $R_{Y}$ to two uniform values $u$ and $v$ using the distribution functions $F_{X}$ and $G_{Y}$ of the two stocks.

- Determine whether the stock pair $(u, v)$ falls outside the confidence bands as predicted by the conditional copula function. Should $C(U \mid V=v)>p$ and $C(V \mid U=u)<1-p$ it would be an indication to sell stock $X$ and buy stock $Y$. For the SSF trading strategy it is necessary to determine which of the two stocks showed the biggest relative move. In other words, given that $(u, v)$ falls outside the confidence bands, then if $C(U \mid V=v)>1-C(V \mid U=$ $u$ ) sell the SSF on stock $X$, otherwise, buy the SSF on stock $Y$. Alternatively, if $C(U \mid V=v)<$ $1-p$ and $C(V \mid U=u)>p$ and if $1-C(U \mid V=v)>C(V \mid U=u)$ then buy the SSF on stock $X$, otherwise sell the SSF on stock $Y$. If the stock pair $(u, v)$ does not fall outside the confidence bands, no trade is executed.

- Determine how many of the SSF contracts to buy or sell and execute the trade.

- Exit the trade when the stock underlying the SSF contract reverts to the expected historical relationship. For instance, when buying the SSF on stock $X$, a profit will be locked in when unwinding the trade after the price of stock $X$ increased because at that time the SSF price will also be higher.

Compared to the pairs-trading strategy, the SSF trading strategy is more exposed to market risk, because the investor holds a SSF on only one of the stocks. There is thus not the natural hedging effect as there is for the pairs-trade, where a loss on one stock may be offset by a profit in the other stock.

To reduce the riskiness of the strategy, the idea is to monitor enough stock pairs to construct a diversified portfolio. The strategy is a short-term strategy, which means that the portfolio will have to be managed actively.

\section{DRIFT IN THE STOCK PRICE}

It is important to understand the drift of a stock price. When a stock price has a positive drift, it is expected that the stock price will increase. By entering into a pairs-trading strategy, the trader will incur more risk when selling the stock with the positive drift, because the chances are that the trader will have to buy the stock back at a higher price when unwinding the position. Similarly, when a stock has a negative drift, it is expected that the stock price will decrease. When the trader buys the stock with the negative drift, there is a big risk that the trader will have to sell the stock at a lower price when unwinding the position.

The strength of the drift also has to be considered. When there are two stocks both with a strong positive drift, then the stock with the stronger drift should provide a bigger return, but this also means that there is a higher risk when investing in this stock.

When executing a pairs-trading strategy using stocks with strong positive or negative drifts, it is necessary to unwind the positions relatively quickly. It is the only way to take advantage of a mispricing in the market and still lock in a profit.

It is also important to determine how many stocks to buy and sell. There are various techniques to determine this, for instance, to calculate the Sharpe ratio of each stock. The Sharpe ratio is the average return of the stock divided by the stock's standard deviation. The ratio of the two 
stocks' Sharpe ratios then indicates how many of the stocks to buy or sell. The problem with the Sharpe ratio is that it is not very stable over time.

In the application of the pairs-trading strategy discussed in Section 3, the ratio of the drift of the two stocks is used as an indicator of how many stocks to buy or sell. The drifts of the stocks are estimated by calculating daily moves in the stock price and then calculating the average of the daily moves over a certain historical period

$$
\operatorname{drift}_{X}=\frac{1}{n} \sum_{j=2}^{n}\left(P_{X, j}-P_{X, j-1}\right)
$$

and

$$
\operatorname{drift}_{Y}=\frac{1}{n} \sum_{j=2}^{n}\left(P_{Y, j}-P_{Y, j-1}\right)
$$

with all symbols as defined before. For every unit of stock $X$ that is bought, $\left|\frac{\text { drift }_{X}}{\text { drift }_{Y}}\right|$ units of stock $Y$ are sold, and vice versa. The drift of a stock is time-dependent, which implies that the period over which it is derived has to be chosen with care.

\section{TRADING COSTS}

Trading in equities is done through brokerage firms. When trading in equities, there are various costs that have to be taken into account. The trading costs involved and discussed in this section are those relevant when trading in South Africa on the Johannesburg Stock Exchange (JSE). The trading costs differ slightly between different institutions. For instance, the costs published by Sanlam (2012) cover:

- A monthly account maintenance fee payable to the broker.

- A brokerage fee that is a fixed percentage of the transaction value.

- A securities transfer tax (STT) of $0.25 \%$ on purchases.

- An investor protection levy of $0.0002 \%$ applies to all trades.

- Vat of $14 \%$ on all the trading costs.

\section{APPLICATION OF THE TRADING STRATEGIES}

In this section back-test analyses are performed on various stock pairs to test the proposed trading strategies over time.

\subsection{Selecting the stock pairs}

To determine which stock pairs to include in the analysis, the correlations between some of the most liquid stocks traded on the JSE are analysed. TABLE $l$ is an extract of the stocks that showed the highest correlation. The stock codes correspond with those used by the JSE. 


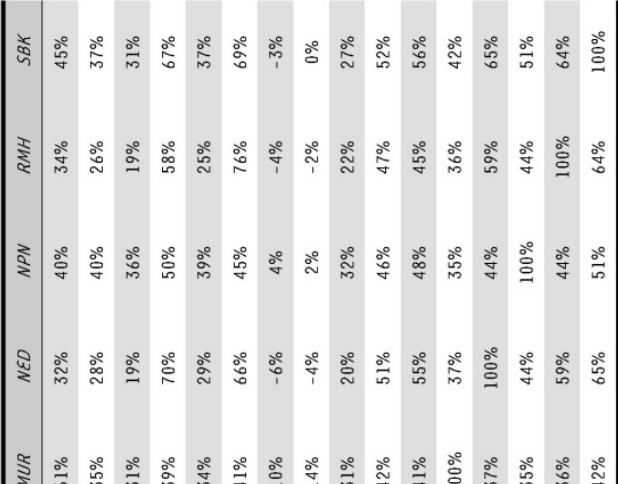

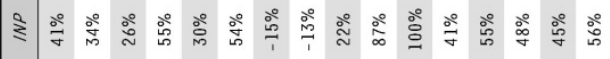

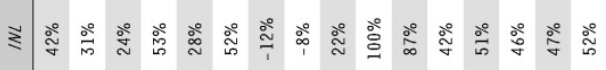

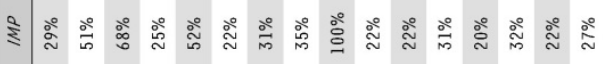

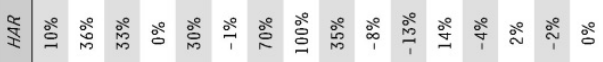

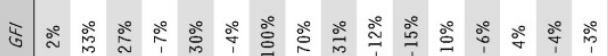

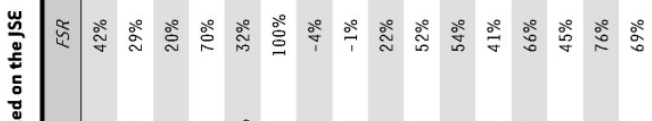

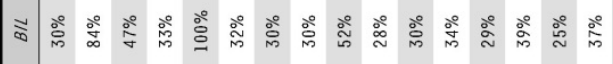

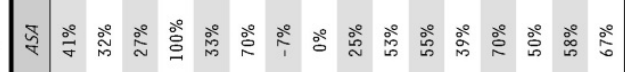

ई

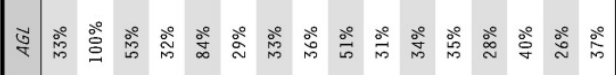

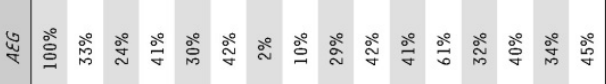

茅 
The correlations in TABLE 1 have been calculated using daily stock price returns from March 2008 to March 2009 and using Spearman's rho as the correlation measure. Some of the noteworthy correlations are between AGL and BIL which is $84 \%$; FSR and RMH, which is $76 \%$ correlated; and INP and INL, which is $87 \%$ correlated.

Nelson (2006) lists 22 Archimedean copulas. To determine which copulas to use for each of the stock pairs that are considered in the back-test analysis, all 22 Archimedean copulas are fitted to each stock pair and then the Kolmogorov-Smirnov goodness-of-fit test is used to determine which copula fits best.

The copula parameters are estimated using the canonical maximum likelihood (CML) method where the empirical distribution function is used as estimate of the marginal distribution functions. The approach entails maximising the log-likelihood function (Cherubini et al., 2004):

$$
\hat{\alpha}=\arg \max \sum_{j=1}^{n} \ln c\left(u_{j}, v_{j}\right)
$$

where $c($.$) denotes the copula density function. In practice the CML approach is only useful when$ there is enough data available to efficiently calculate the empirical marginal distribution functions.

TABLE 2 shows the Kolmogorov-Smirnov test statistics and $p$-values for the stock pairs considered. In five of the seven stock pairs the N14 copula shows a good fit. The N14 copula allows for positive dependence only, and captures both upper- and lower-tail dependence. In two cases the N13 copula shows the best fit. The N13 copula captures no tail dependence. Tail dependence is a measure of the dependence between the variables in the upper-right quadrant (upper-tail dependence) and in the lower-left quadrant (lower-tail dependence) in $I^{2}$.

TABLE 2: Goodness-of-fit test statistics and $p$-values for various stock pairs

\begin{tabular}{lcccc}
\hline Equity Pair & Copula & Copula Parameter & $\begin{array}{c}\text { Kolmogorov-Smirnov } \\
\text { Test Statistic }\end{array}$ & p-value \\
\hline AEG vs. MUR & $\mathrm{N} 13$ & 2.321 & 1.103 & 0.961 \\
AGL vs. BIL & $\mathrm{N} 14$ & 1.846 & 0.949 & 0.928 \\
AMS vs. IMP & $\mathrm{N} 14$ & 1.400 & 0.901 & 0.985 \\
ASA vs. NED & $\mathrm{N} 13$ & 2.795 & 1.407 & 0.53 \\
FSR vs. RMH & $\mathrm{N} 14$ & 1.975 & 0.752 & 0.998 \\
GFI vs. HAR & $\mathrm{N} 14$ & 1.833 & 0.839 & 0.987 \\
INP vs. INL & $\mathrm{N} 14$ & 2.699 & 0.518 & 0.999 \\
\hline
\end{tabular}

Source: JSE online data base; author/s calculations

In the back-test analysis, it is assumed that the same copula can be used to model the dependence structure between an equity-pair under all economic conditions. For each back-test the copula parameter is estimated using only the most recent market data available at the time. 


\subsection{Application of the pairs-trading strategy}

In this section the pairs-trading strategy is illustrated using two of the top 40 stocks on the JSE that are relatively highly correlated. The two stock codes are FSR and RMH, and their historical closing prices are shown in FIGURE 5. The FSR and RMH stocks are both banking stocks and relatively highly correlated.

TABLE 2 shows that the N14 copula can be used to model the dependence structure between FSR and RMH. The N14 copula is defined as

$$
\begin{aligned}
& C(u, v)=\left(1+\left[\left(u^{-1 / \alpha}-1\right)^{\alpha}+\left(v^{-1 / \alpha}-1\right)^{1 / \alpha}\right]^{1 / \alpha}\right)^{-\alpha} \\
& \text { for } \alpha \in[1, \infty)
\end{aligned}
$$

The historical closing prices of FSR and RMH are analysed to determine how profitable the pairstrading strategy is over time using a $95 \%$ confidence level. The confidence level was selected based on a back-test analysis that shows using $95 \%$ seems to lead to appropriate trading opportunities to be identified.

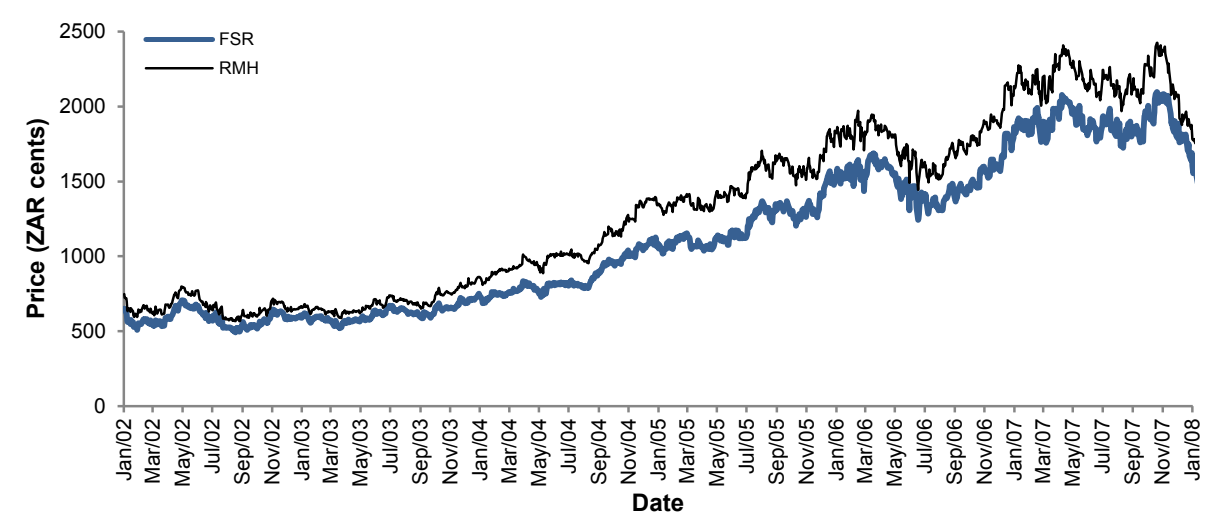

\section{FIGURE 5: Daily historical FSR and RMH closing price series}

\section{Source: JSE closing prices}

\section{The simulation study is performed as follows:}

Step 1: $\quad$ The historical data for the first year forms the training sample.

Step 2: $\quad$ Estimate the copula parameter using the training sample dataset.

Step 3: Assume that the last set of observations in the training sample is the most recent market observed values.

Step 4: Using the methodology discussed in Section 3, determine whether there is a pairstrading opportunity. It is assumed that there can only be one active pairs-trade at any time, so if there is no active trade in the portfolio and there is a pairs-trading opportunity, execute the trade and go on to Step 6. 
Step 5: If there is an active trade in the portfolio, determine whether it is profitable to exit the trade. If it is profitable, then the trade is reversed. If it is not profitable, but the pairs-trade has been in the portfolio for a week, then the trade is also exited. It is assumed that the pairs-trade has to be exited within a week, because it is a shortterm strategy. In the simulation study the trade is exited after a week, even if it results in a loss.

Step 6: $\quad$ Add one day's data to the training sample and return to Step 2.

A subset of the pairs-trading opportunities identified for FSR and RMH is shown in TABLE 3. A short position (selling the share) is indicated with a minus $l$ and a long position (buying the share) with a plus 1 . The approach discussed in Section 5 is used to determine how many shares to buy and sell.

For every FSR share that is bought (sold), $\left|\frac{\text { drift }_{F S R}}{\operatorname{drift}_{R M H}}\right|$ units of RMH are sold (bought).

The alpha in TABLE 3 indicates the estimated N14 copula parameter. It is evidently high initially, decreases towards the beginning of 2008 and then increases again towards the beginning of 2009. The lower alpha values indicate a lower correlation between the two stocks over during 2008. The increase of the estimated correlation in 2008 is to be expected, since it is considered to have been a stress period in the equity market.

In the back-test analysis, there were 87 pairs-trading opportunities from January 2002 to March 2009. There may have been more trading opportunities that are not captured, because only one trade for the pair of stocks was allowed at any time. Another possible shortcoming of the backtest analysis is that daily closing prices are used. With real-time data many more trading opportunities may be possible. The results indicate that most of the pairs-trading opportunities are in volatile periods, which, in this example, refers to the period from 2006 onwards.

TABLE 3: The pairs-trading opportunities identified from January 2007 to March 2009 for FSR and RMH.

\begin{tabular}{lccccc}
\hline Trade Date & Buy/SellFSR & Buy/Sell RMH & $\begin{array}{c}\text { No. of Shares } \\
\text { FSR }\end{array}$ & $\begin{array}{c}\text { No. of Shares } \\
\text { RMH }\end{array}$ & $\alpha$ \\
\hline 08-Jan-07 & -1 & 1 & 1 & 0.63 & 2.34 \\
23-Jan-07 & -1 & 1 & 1 & 0.57 & 2.29 \\
\hline 21-Feb-07 & -1 & 1 & 1 & 0.74 & 2.28 \\
03-Apr-07 & 1 & -1 & 1 & 0.56 & 2.41 \\
17-Apr-07 & -1 & 1 & 1 & 0.69 & 2.33 \\
19-Apr-07 & -1 & 1 & 1 & 0.68 & 2.29 \\
\hline 24-May-07 & 1 & -1 & 1 & 0.68 & 2.24 \\
31-May-07 & 1 & -1 & 1 & 0.87 & 2.22 \\
17-Aug-07 & -1 & 1 & 1 & 0.82 & 2.05 \\
23-0ct-07 & -1 & 1 & 1 & 0.77 & 2.01 \\
19-Nov-07 & 1 & -1 & 1 & 0.66 & 1.96 \\
22-Nov-07 & 1 & -1 & 1 & 0.66 & 1.90
\end{tabular}




\begin{tabular}{|c|c|c|c|c|c|}
\hline Trade Date & Buy/Sell FSR & Buy/Sell RMH & $\begin{array}{c}\text { No. of Shares } \\
\text { FSR }\end{array}$ & $\begin{array}{c}\text { No. of Shares } \\
\text { RMH }\end{array}$ & $\alpha$ \\
\hline 28-Nov-07 & 1 & -1 & 1 & 0.59 & 1.90 \\
\hline 30-Nov-07 & 1 & -1 & 1 & 0.64 & 1.87 \\
\hline $04-D e c-07$ & -1 & 1 & 1 & 0.64 & 1.87 \\
\hline 14-Dec-07 & -1 & 1 & 1 & 0.72 & 1.84 \\
\hline 11-Jan-08 & 1 & -1 & 1 & 0.74 & 1.77 \\
\hline 30-Jan-08 & 1 & -1 & 1 & 0.86 & 1.75 \\
\hline $04-F e b-08$ & -1 & 1 & 1 & 0.65 & 1.78 \\
\hline 03-Mar-08 & 1 & -1 & 1 & 0.66 & 1.75 \\
\hline 13-Mar-08 & 1 & -1 & 1 & 0.7 & 1.75 \\
\hline 19-Mar-08 & 1 & -1 & 1 & 0.74 & 1.75 \\
\hline 03-Apr-08 & 1 & -1 & 1 & 0.74 & 1.75 \\
\hline 01-Jul-08 & 1 & -1 & 1 & 0.65 & 1.79 \\
\hline $31-J u l-08$ & -1 & 1 & 1 & 0.61 & 1.86 \\
\hline 13-Aug-08 & 1 & -1 & 1 & 0.6 & 1.85 \\
\hline $01-S e p-08$ & -1 & 1 & 1 & 0.8 & 1.88 \\
\hline $03-0 c t-08$ & 1 & -1 & 1 & 0.59 & 1.91 \\
\hline $10-0 \mathrm{ct}-08$ & 1 & -1 & 1 & 0.52 & 1.90 \\
\hline 04-Nov-08 & -1 & 1 & 1 & 0.56 & 1.96 \\
\hline $10-$ Nov-08 & -1 & 1 & 1 & 0.57 & 1.88 \\
\hline $20-$ Nov-08 & 1 & -1 & 1 & 0.58 & 1.85 \\
\hline 01-Dec-08 & -1 & 1 & 1 & 0.5 & 1.90 \\
\hline $15-$ Dec-08 & -1 & 1 & 1 & 0.56 & 2.00 \\
\hline 24-Dec-08 & -1 & 1 & 1 & 0.54 & 2.05 \\
\hline 14-Jan-09 & -1 & 1 & 1 & 0.49 & 2.06 \\
\hline 21-Jan-09 & -1 & 1 & 1 & 0.55 & 2.08 \\
\hline 26-Jan-09 & -1 & 1 & 1 & 0.66 & 2.06 \\
\hline 09-Feb-09 & -1 & 1 & 1 & 0.62 & 2.10 \\
\hline $12-$ Feb- 09 & 1 & -1 & 1 & 0.59 & 2.10 \\
\hline 03-Mar-09 & 1 & -1 & 1 & 0.53 & 2.08 \\
\hline 06-Mar-09 & -1 & 1 & 1 & 0.62 & 2.02 \\
\hline
\end{tabular}

Source: JSE online data base; authors' calculations

To determine profits and losses, it is assumed that every time a pairs-trade is possible, the trader has ZAR1 000000 available to buy the shares (excluding trading costs), in other words, when buying FSR shares it follows that

$$
m_{F S R} \times 1 \times P_{F S R}=1000000
$$


Where $m_{F S R}$ denotes the number of FSR shares that are bought at a price $P_{F S R}$.

TABLE 4 shows an extract of the profits and losses of the FSR-RMH pairs-trading strategy. The profits and losses in the last column are realised every time the trade is unwound. FIGURE 6 shows the profits and losses from the FSR-RMH analysis before and after trading costs are taken into account. The trading costs are calculated as discussed in Section 6 and assuming a brokerage fee of $0.5 \%$.

TABLE 4: An extract from 2008 onwards of the profits and losses of the FSR-RMH pairs-trading strategy

\begin{tabular}{|c|c|c|c|c|c|c|}
\hline TRADE DATE & $\begin{array}{c}\text { FSR } \\
\text { EXPOSURE }\end{array}$ & FSR PROFIT & $\begin{array}{c}R M H \\
\text { EXPOSURE }\end{array}$ & $\begin{array}{c}\text { RMH } \\
\text { PROFIT }\end{array}$ & $\begin{array}{c}\text { PROFIT } \\
\text { (BEFORE } \\
\text { COST) }\end{array}$ & $\begin{array}{c}\text { PROFIT } \\
\text { (AFTER } \\
\text { COST) }\end{array}$ \\
\hline 11 January 08 & 1000000 & & -1156224 & & & \\
\hline 14 January 08 & -1030000 & 30000 & 1160339 & -4115 & 25885 & -5363 \\
\hline 30 January 08 & 1000000 & & -1404689 & & & \\
\hline 31 January 08 & -993417 & -6583 & 1336330 & 68359 & 61776 & 27871 \\
\hline 04 February 08 & -997500 & & 1000000 & & & \\
\hline 06 February 08 & 915583 & 81917 & -945324 & -54676 & 27241 & -517 \\
\hline 03 March 08 & 1000000 & & -1020158 & & & \\
\hline 12 March 08 & -937187 & -62813 & 956444 & 63714 & 901 & -27291 \\
\hline 13 March 08 & 1000000 & & -1126471 & & & \\
\hline 17 March 08 & -954151 & -45849 & 1058805 & 67666 & 21818 & -7900 \\
\hline 19 March 08 & 1000000 & & -1209569 & & & \\
\hline 25 March 08 & -1014539 & 14539 & 1209569 & 0 & 14539 & -17290 \\
\hline 03 April 08 & 1000000 & & -1178313 & & & \\
\hline 04 April 08 & -1004748 & 4748 & 1172598 & 5715 & 10463 & -20872 \\
\hline 01 July 08 & 1000000 & & -1047298 & & & \\
\hline 02 July 08 & -1004584 & 4584 & 1033953 & 13345 & 17928 & -11473 \\
\hline 31 July 08 & -1053518 & & 1000000 & & & \\
\hline 07 August 08 & 1007521 & 45997 & -935385 & -64615 & -18618 & -47431 \\
\hline 13 August 08 & 1000000 & & -940759 & & & \\
\hline 14 August 08 & -1012443 & 12443 & 944678 & -3919 & 8523 & -19488 \\
\hline 01-Sep-08 & -808962 & & 1000000 & & & \\
\hline 08-Sep-08 & 848675 & -39713 & -1053864 & 53864 & 14151 & -12566 \\
\hline $03-0 c t-08$ & 1000000 & & -944424 & & & \\
\hline $06-0 c t-08$ & -919003 & -80997 & 837494 & 106930 & 25933 & -695 \\
\hline
\end{tabular}




\begin{tabular}{|c|c|c|c|c|c|c|}
\hline TRADE DATE & $\begin{array}{c}\text { FSR } \\
\text { EXPOSURE }\end{array}$ & FSR PROFIT & $\begin{array}{c}R M H \\
\text { EXPOSURE }\end{array}$ & $\begin{array}{c}\text { RMH } \\
\text { PROFIT }\end{array}$ & $\begin{array}{c}\text { PROFIT } \\
\text { (BEFORE } \\
\text { COST) }\end{array}$ & $\begin{array}{c}\text { PROFIT } \\
\text { (AFTER } \\
\text { COST) }\end{array}$ \\
\hline $10-0$ ct-08 & 1000000 & & -819053 & & & \\
\hline $15-0 c t-08$ & -1039945 & 39945 & 819409 & -356 & 39589 & 13202 \\
\hline 04-Nov-08 & -1146687 & & 1000000 & & & \\
\hline $05-N o v-08$ & 1108946 & 37741 & -1015674 & 15674 & 53415 & 22742 \\
\hline $10-N o v-08$ & -1123389 & & 1000000 & & & \\
\hline 11-Nov-08 & 1073030 & 50359 & -969298 & -30702 & 19657 & -10252 \\
\hline $20-N o v-08$ & 1000000 & & -976532 & & & \\
\hline 21-Nov-08 & -1000000 & 0 & 940774 & 35758 & 35758 & 7645 \\
\hline 01-Dec-08 & -1325406 & & 1000000 & & & \\
\hline 02-Dec-08 & 1168767 & 156639 & -934263 & -65737 & 90902 & 59167 \\
\hline 15-Dec-08 & -1136173 & & 1000000 & & & \\
\hline 17-Dec-08 & 1206522 & -70349 & -1076923 & 76923 & 6574 & -25165 \\
\hline 24-Dec-08 & -1215013 & & 1000000 & & & \\
\hline 29-Dec-08 & 1238379 & -23366 & -1025952 & 25952 & 2587 & -29584 \\
\hline 14 January 09 & -1342672 & & 1000000 & & & \\
\hline 15 January 09 & 1247744 & 94928 & -977358 & -22642 & 72286 & 39529 \\
\hline 21 January 09 & -1166930 & & 1000000 & & & \\
\hline 22 January 09 & 1110006 & 56924 & -985135 & -14865 & 42059 & 11493 \\
\hline 26 January 09 & -969656 & & 1000000 & & & \\
\hline 02 February 09 & 1013400 & -43744 & -1015348 & 15348 & -28396 & -57238 \\
\hline 09 February 09 & -1052488 & & 1000000 & & & \\
\hline 10 February 09 & 1038819 & 13669 & -1018644 & 18644 & 32313 & 2817 \\
\hline 12 February 09 & 1000000 & & -954838 & & & \\
\hline 13 February 09 & -987569 & -12431 & 906080 & 48758 & 36327 & 8710 \\
\hline 03 March 09 & 1000000 & & -878773 & & & \\
\hline 04 March 09 & -1039427 & 39427 & 866993 & 11780 & 51206 & 24011 \\
\hline 06 March 09 & -1048326 & & 1000000 & & & \\
\hline 09 March 09 & 1012639 & 35687 & -999446 & -554 & 35134 & 5995 \\
\hline
\end{tabular}

Source: JSE online data base; authors' calculations

The pairs-trading strategy is an easy way to pick up trading opportunities in the market. However, the stocks considered have to be relatively liquid. Liquidity implies that it is possible 
to enter or exit a trade relatively easily when required. The strategy is built on the assumption that stocks will always revert to their historical relationship. Depending on how strong the mean reversion is assumed to be, the strategy is usually short-term and requires active management.

Ignoring the trading costs, the pairs-trading strategy leads to a profit in most cases. The position in one of the shares often shows a profit, while the position in the other share shows a loss. However, the aggregated position in most cases leads to a profit. This result is a function of the methodology used to determine the number of each share to trade. By choosing the right combination of shares, in other words, knowing how many of each share to buy and sell, the strategy will lead to a profit more often than not. This result also highlights one of the advantages of the pairs-trading strategy, which is that the two stocks in a pair act as hedges for each other.

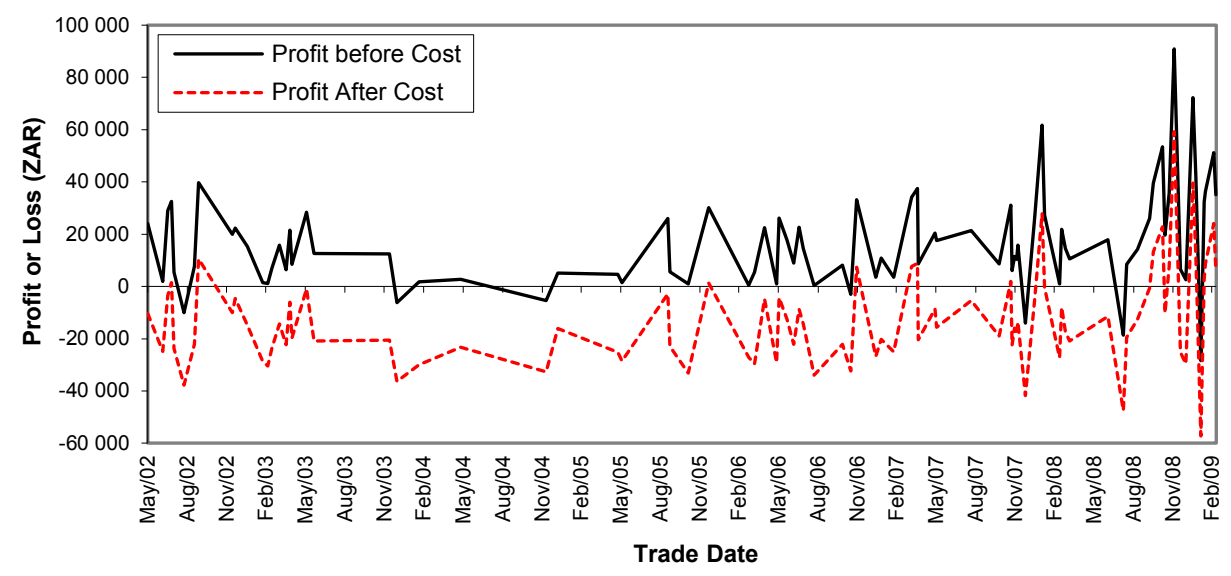

\section{FIGURE 6: Profits and losses from the FSR-RMH analysis before and after trading costs are taken into account}

\section{Source: Representation of simulation study}

Another interesting observation from the empirical analysis is that it seems as though there are more trading opportunities available when the market is relatively volatile. Instances of extremely low volatility result in few opportunities to benefit from market mispricing (Pictet Alternative Investments, 2010).

In times of stress the correlation between the equities increases, because they all lose value at around the same time. The increased dependence is spurious in the sense that it does not imply that more stock pairs can now be monitored for trading opportunities. There is a difference between stressed market conditions and the actual dependence between stocks that can be monitored for trading opportunities.

It is relatively difficult to construct a portfolio of pairs-trades, since the trading opportunities for different stocks do not occur at the same time, and the pairs-trade strategy is a short-term strategy. In general, many stock pairs have to be monitored to be able to construct a diversified portfolio of stocks.

The main drawback of the pairs-trading strategy is that, in most cases, after the trading costs are taken into account, the profit is eliminated and often converted into a loss. The fact that 
closing prices are used in the analysis also implies that the bid/offer spread has not been taken into account.

In the next section single stock futures are considered as an alternative. Single stock futures contracts allow the trader to have more exposure to the stock market, with less capital required and fewer trading costs.

\subsection{Application of the SSF Trading Strategy}

In this section the SSF trading strategy is applied to various stock pairs by following a set of fixed rules in a simulation study. In order to simplify the simulation study, the following assumptions are made:

- The investor always invests only in the near-dated SSF contract.

- The investor never rolls a contract; in other words, if the investor holds the March contract until expiry, the position is closed out on the maturity date.

- Trading costs are taken into account.

- The trading decision is made by analysing the underlying shares, even though trades are executed on the SSF contracts.

- Every time a trading opportunity presents itself, $n_{X}$ SSF contracts are bought or sold where $n_{X}$ is determined by setting the exposure $V_{X}=1000000$ and using the bid or offer price of the SSF depending on whether the SSF is bought or sold.

- The trade is reversed within one month even if it would lead to a loss. The reasoning is that the proposed strategy is supposed to be a short-term strategy.

- A $95 \%$ confidence level is used.

The following assumptions regarding trading costs are made in the simulation study:

- the commission is $0.4 \%$ the brokerage fee is ZAR 101;

- the initial margin for all stocks is $20 \%$ and trading costs as specified in JSE (2010);

- SSF bid and offer prices from JSE are used.

The SSF data used in the analysis covers the period from April 2003 to December 2008. The SSF strategy has been applied to six stock pairs. The profits-and-losses identified from 2005 to 2008 are shown in TABLE 5 for each of the four futures contracts in a year. All numbers denote South African Rand (ZAR) amounts.

TABLE 5: Profits and Losses from 2002 to 2008 resulting from the SSF trading strategy after all trading costs are taken into account for various stock pairs

\begin{tabular}{rrrrrrrrr}
\hline \multirow{2}{*}{ yEAR } & $\begin{array}{l}\text { Near- } \\
\text { dated } \\
\text { Future }\end{array}$ & AGL vs. & AMS vs. & \multicolumn{1}{c}{$\begin{array}{c}\text { GFIvs. } \\
\text { IMP }\end{array}$} & $\begin{array}{c}\text { AEG vs. } \\
\text { MAR }\end{array}$ & $\begin{array}{c}\text { ASAvs. } \\
\text { NED }\end{array}$ & $\begin{array}{c}\text { INPvs. } \\
\text { INL }\end{array}$ & \multicolumn{1}{c}{ TOTAL } \\
\hline 2005 & Sep-05 & & -9349 & 11664 & & & & 2316 \\
& Dec-05 & & 15727 & 5887 & & & 21614 \\
2006 & Mar-06 & 2606 & 7087 & -171026 & & -161333 \\
& Jun-06 & & 19367 & 70741 & & -38577 & 51531
\end{tabular}




\begin{tabular}{|c|c|c|c|c|c|c|c|c|}
\hline YEAR & $\begin{array}{l}\text { Near- } \\
\text { dated } \\
\text { Future }\end{array}$ & $\begin{array}{c}A G L \text { vs. } \\
B / L\end{array}$ & $\begin{array}{c}A M S \text { vs. } \\
\text { IMP }\end{array}$ & $\begin{array}{c}\text { GFI vs. } \\
\text { HAR }\end{array}$ & $\begin{array}{c}A E G v s . \\
M U R\end{array}$ & $\begin{array}{c}A S A \text { vs. } \\
N E D\end{array}$ & $\begin{array}{c}\text { INP vs. } \\
\text { INL }\end{array}$ & $\begin{array}{c}\text { TOTAL } \\
\text { P\&L }\end{array}$ \\
\hline & Sep-06 & 13407 & & 25562 & 3067 & & 2170 & 44206 \\
\hline & Dec-06 & & & & & & 5422 & 5422 \\
\hline \multirow[t]{4}{*}{2007} & Mar-07 & & 5110 & & & & & 5110 \\
\hline & Jun-07 & 19680 & 3345 & & & & & 23025 \\
\hline & Sep-07 & & 12993 & 45925 & & & & 58918 \\
\hline & Dec-07 & 36061 & 45567 & & & & & 81628 \\
\hline \multirow[t]{4}{*}{2008} & Mar-08 & 27251 & 1137 & & 17871 & & 10252 & 56511 \\
\hline & Jun-08 & -147668 & 4765 & & 24592 & & 1259 & -117052 \\
\hline & Sep-08 & & -34368 & 82708 & 74386 & 5665 & 109723 & 238113 \\
\hline & Dec-08 & 112019 & 184123 & 157937 & 188456 & & 107038 & 749574 \\
\hline
\end{tabular}

Source: JSE online data base; authors' calculations

\section{Some interesting observations from the analysis:}

- In 2005 very few trading opportunities have been identified.

- In most years a net profit has been realised, except in 2006 where there was a big trading loss on the GFI-HAR pair. The big loss occurred because the contract expired and the position was closed-out at a loss as per the rules of the simulation study.

- The greatest number of trading opportunities occurred in 2008 , which may be explained by the volatility in the equity market in that year.

- The AEG-MUR, GFI-HAR and INP-INL pairs created the biggest net profits in 2008.

The empirical analyses using SSF contracts show that the strategy can result in losses. This implies that the strategy has to be applied with care, and it is very important to monitor a sufficient number of stock pairs in order to put together a diversified portfolio, so as to reduce the market risk of the positions.

The results are positive in that in most years the SSF trading strategy led to net profits. This is particularly noteworthy considering that the strategy is purely mechanistic, driven by formulas and no company-specific information is taken into account.

\section{CONCLUDING REMARKS}

Bivariate copulas capture all the information of the dependence structure between two stocks, which is ideal when determining trading opportunities. The asymmetry and heavy-tail characteristics of stock price returns are accounted for in the actual marginal distribution functions that are modelled; no simplifying assumptions are applied, such as that of a singular use of Gaussian distribution functions.

The number of trading opportunities depends on the confidence level considered. The choice of confidence level is subjective, and so the decision should be taken with care. Using a confidence level that is too low will lead to a great number of trading opportunities being identified, but 
those trades are considered to be more risky, because there is a reduced probability that the stocks will mean-revert as expected. The confidence level is also determined by the level of dependence between the two stocks; the stronger the dependence between two stocks, the lower the confidence level may be. In Section 7 a confidence level of $95 \%$ was used. Other empirical analyses showed that given that the correlation is high enough, a confidence level of $80 \%$ can also be used successfully.

In general, it is expected that a trader will accommodate more risk when selling a stock with positive drift, since the trader will most probably have to buy back the stock at a higher price when unwinding the position. A similar argument holds for a stock that has negative drift; the stock price is expected to decrease, which means that when the trader buys a stock with the negative drift, there is a big risk that the trader will have to sell the stock at a lower price when unwinding the position. However, the results of the empirical analyses do not support these assertions. There is no consistent proof that selling the stock with the negative drift or buying back the stock with positive drift will result in a loss. In the analyses the drifts of the stocks are only taken into account when determining the ratio of stocks to buy or sell in the pairs-trading strategy.

The strategies considered are short-term and require active monitoring and managing. The success of the strategies is strongly dependent on the liquidity of the stocks. It has to be possible to enter or exit trades immediately when required.

It is interesting to note that stocks very often exhibit both upper and lower tail-dependence. This is an indication that stocks tend to move together more closely in times of stress as well as in times when the equities show aggressive growth. The fact that the heavy tails of the stock returns are accommodated in the marginal distribution functions implies that a stress move in one stock will not automatically trigger a trading signal. The copula function, when applied in pairs-trading strategies, allows for the fact that any stress move in one stock may result in a similar stress move in the other, while the trading signal is only triggered when the relationship breaks down. The impact of heavy tails in the South African stock return distributions is therefore masked and would not necessarily affect the observed outcome.

The empirical analyses indicated more trading opportunities when the market is volatile. In an environment of extremely low volatility there are relatively few opportunities to benefit from market mispricing.

A hedge fund may be more inclined to use a cash-neutral strategy such as a pairs-trading approach, which requires no net cash in order to enter or perform the transaction, as the two instruments are simultaneously bought and sold.

The results of the pairs-trading strategy are disappointing in that even though the strategy in most cases leads to a profit, these profits are consumed by the trading costs. The results of the SSF trading strategy are more positive in that, in most years, a net profit is locked in even after trading costs are taken into account. The SSF trading strategy definitely has potential when a statistical arbitrage approach to the construction of a portfolio is sought.

\section{LIST OF REFERENCES}

Agarwal, N., Madhogaria, V. \& Narayanan, S. (2004). Simulated Trading - An Analysis of Pairs Trading. Tech. rept. Stockholm School of Economics. 
Allen, D.E., Golab, A. \& Powell, R. (2010). Volatility and correlations for stock markets in the emerging economies of Central and Eastern Europe: Implications for European investors. Working Paper 1001. School of Accounting, Finance and Economics and FEMARC Working Paper Series. Edith Cowan University. June

Andersen, T.G, Bollerslev, T., Christoffersen, P.F. \& Diebold, F.X. (2007). Practical Volatility and Correlation Modeling for Financial Market Risk Management, In: The Risks of Financial Institutions, ed. Mark Carey and René M. Stulz, University of Chicago Press, pp. 513-548.

Black, F. \& Litterman, R. (1990). Asset allocation: combining investor views with market equilibrium. Research paper. Goldman Sachs Fixed Income Research. (More information is available from http://www.blacklitterman.org/.)

Chan, E.P. (2009). Quantitative Trading, John Wiley \& Sons Inc.

Cherubini, U., Luciano, E., \& Vecchiato, W. (2004). Copula Methods in Finance. John Wiley \& Sons Inc.

Chu, B. (2011). Recovering copulas from limited information and an application to asset allocation. Journal of Banking \& Finance, 35(7), pp. 1824-1842.

Connor, G. \& Lasarte, T. (2004). An Introduction to Hedge Fund Strategies. Research Report. Hedge Fund Research Programme. Financial Markets Group. London School of Economics.

Do, B., Fa, R. \& Hamza, K. (2006). A New Approach to Modeling and Estimation for Pairs Trading. In: Proceedings of 2006 Financial Management Association European.

Genest, C., \& Rémillard, B. (2005). Validity of the Parametric Bootstrap for Goodness-of-of-fit Testing in Semiparametric Models. Annales de I'Institut Henri Poincaré: Probabilités et statistiques, 44, pp. 1096-1127.

Genest, C., Rémillard, B. \& Beaudoin, D. (2007). Goodness-of-fit tests for copulas: A review and a power study. Insurance Mathematics and Economics, 44(2), pp. 199-213.

Ghysels, E., Plazzi, A. \& Valkanov, R. (2011). Conditional Skewness of Stock Market Returns in Developed and Emerging Markets and its Economic Fundamentals. Research Paper. Department of Finance. Kenan-Flagler Business School and Department of $\varepsilon$ conomics. UNC. November.

Hennessy, D.A. \& Lapan, H.E. (2002). The use of Archimedean copulas to model portfolio allocations. Mathematical Finance, 12(2), pp. 143-154.

Ibragimov, M., Davidova, Z. \& Khamidov, R. (2010). Heavy-Tailedness and Volatility in Emerging Foreign Exchange Markets: Theory and Empirics. Working paper 10/06E. Economics Education and Research Consortium.

Joe, H. (1997). Multivariate models and dependence concepts (monographs on statistics and applied probability 73). Chapman \& Hall/CRC.

JSE. (2010). Sing/e Stock Futures. Product Brochure, Johannesburg Stock Exchange. [Online] Available: http://www.jse.co.za/Products/Equity-Derivatives-Market/Equity-Derivatives-ProductDetail/Single_Stock_Futures.aspx. (Accessed 6 May 2013)

Khedhiri, S. and Muhammad, N. (2008). Empirical Analysis of the UAE Stock Market Volatility. International Research Journal of Finance and Economics, 15, pp. 249-260.

Markowitz, H.M. (1952). Portfolio Selection. The Journal of Finance, 7(1), pp. 77-91.

McNeil, A.J., Frey, R. \& Embrechts, P. (2005). Quantitative risk management: concepts, techniques, and tools. Princeton University Press. 
Meucci, A. (2001). A common pitfall in mean-variance asset allocation. Willmott.

Meucci, A. (2005). Beyond Black-Litterman: Views on Non-Normal Markets. Tech. rept. Available at SSRN: http://ssrn.com/abstract $=848407$.

Meucci, A. (2006). Beyond Black-Litterman in practice: a five-step recipe to input views on nonnormal markets. Risk, 19(9), pp. 114-119.

Meucci, A. (2008). The Black-Litterman Approach: Original Model and Extensions. Shorter version in, The Encyclopedia of Quantitative Finance. Wiley. 2010. Available at SSRN:

http://ssrn.com/abstract=1117574 or http://dx.doi.org/10.2139/ssrn.1117574.

Nelsen, R.B. (2006). An Introduction to Copulas, $2^{\text {nd }}$ edition. Springer Science Business Media, Inc.

Oskooe, S.A.P. \& Shamsavari, A. (2011). Asymmetric Effects in Emerging Stock Markets - The Case of Iran Stock Market. International Journal of Economics and Finance, 3(6), pp. 16-24.

Patton, A.J. (2002). Applications of copula theory in financial econometrics. PhD thesis, University of California, San Diego.

Patton, A. J. (2004). On the Out-of-Sample Importance of Skewness and Asymmetric Dependence for Asset Allocation. Journal of Financial Econometrics, 2(1), pp. 130-168.

Patton, A. J. (2012). A review of copula models for economic time series. Journal of Multivariate Analysis, 110, pp. 4-18.

Pictet Alternative Investments (2010). Hedge funds: the case for 'trading strategies'. Research report. Pictet \& Cie. Downloadable from www.pictet.com. September.

Reilly, F.K., \& Brown, K.C. (2006). Investment Analysis and Portfolio Management, $8^{\text {th }}$ edition. Ohio: South-Western, Thomson.

Sanlam. (2012). http://www.sanlamitrade.co.za/OurCosts.aspx.

SBSA. (2006). Single Stock Futures. Product brochure. Standard Bank. Version 5. Downloadable from https://securities.standardbank.co.za/ost/. October.

Sklar, A. (1959). Fonctions de répartition à n dimensions et leurs marges. Publ. Inst. Statist. Univ. Paris 8: 229-231.

Su, C. (2010). Application of EGARCH Model to Estimate Financial Volatility of Daily Returns: The empirical case of China. Master of Science Dissertation. School of Business, Economics and Law. University of Gothenburg.

Thambiah, Y. \& Foscari, N. (2012). New Normal Investing: Is the (Fat) Tail Wagging Your Portfolio? White Paper. Credit Suisse. April. 